\title{
Influence of Occupant Behaviour on the State of Charge of a Storage Battery in a nearly-Zero Energy Building
}

\author{
Pedro F. Pereira ${ }^{l, *}$, and Nuno M. M. Ramos ${ }^{I}$ \\ ${ }^{1}$ CONSTRUCT (LFC), Faculty of Engineering (FEUP), University of Porto, Portugal
}

\begin{abstract}
The development of nearly zero energy buildings (nZEB) is a goal being set for many countries for the next years. In order to achieve that goal, on-site energy generation is needed, and the use of photovoltaic and storage systems is a possible strategy. Hence, the objective of this work is to evaluate the impact that occupant behaviour has on the batteries energy storage systems (BESS) of an nZEB. This study considers as a case study an nZEB with lightweight construction, located in the university campus, and used by different occupants. The case study has $12 \mathrm{PVs}$ located on the root and a second-life BESS from an electrical vehicle (EV). The monitoring system consists of interior $\mathrm{T}, \mathrm{RH}, \mathrm{CO}_{2}$ and energy sensors and an exterior on-site meteorological station. The research started with a state of the art review of the support policies for the on-site photovoltaic generation and energy storage. Different storage charge profiles were obtained as different occupant behaviours were applied to the test building. In total, it were considered three occupant profiles and a base scenario was the unoccupied. The occupant behaviour showed to be determinant in the state of charge of the BESS independently from the impacts in the indoor temperature. The need to know the profile of the occupants before the design of the buildings was enhanced.
\end{abstract}

\section{Introduction}

The environmental threats the world is facing require urgent solutions for sustainable and clean energy sources that can be used in construction. Buildings account for $40 \%$ of energy consumption and $36 \%$ of $\mathrm{EU} \mathrm{CO}_{2}$ emissions. According to the European Union 2020 climate and energy package, the target is $20 \%$ renewable energy in gross final energy consumption. To 2020, the target for Portugal of energy from renewable sources in gross final energy consumption is $31 \%$, and to achieve the $720 \mathrm{MW}$ of solar photovoltaics (PV) systems [1]. Energy performance of buildings is a key element in meeting EU climate and energy targets [2]. Improving the energy performance of buildings is a cost-effective way to fight climate change and improve energy efficiency. From an economic standpoint, the best environmental solutions cannot be guaranteed by regulations that depend primarily on building exterior envelope requirements. Energy efficiency analysis and cost optimisation should consider energy sources and building systems [3]. According to the EPBD recast, minimum energy performance requirements should be set to achieve optimal cost levels for buildings, building units and building elements. (Directive 2018/844 [4]). Since the first recast of Directive 2002/91 / EC [5], the nearly zero energy buildings (nZEB), have received increasing attention. This type of building has energy needs that are partially met by on-site energy production, and its implementation is mandatory in Portugal from
Jan//2019 for public buildings and Jan/2021 for all buildings. The definition of the nZEB was left to the discretion of each member state of the EU by the EPBD. Therefore, there are different approaches and concepts in the EU. In Portugal, the legal document that describes the nZEB was approved in April/2019. Therefore, for the Portuguese nZEB, "the value of the annual nominal heating energy needs shall be less than or equal to $75 \%$ of their maximum value". It also states that "the value of nominal primary energy needs shall be less than or equal to $50 \%$ of its maximum value". Regarding the use of renewable energy sources, the document states that "systems for the use of renewable energy sources must meet at least $50 \%$ of annual primary energy needs". These requirements enhance the use of renewable energies. PV stand out between other types of renewable energies to produce on-site electricity and have been increasing their applicability as their cost decreases [6]. As far as PV technology gets technically and commercially mature, in Portugal, such as in most developed countries, the trend was to reduce Feed-intariffs (FiT) for renewable sources [7]. The FiT started with a value of $0.65 € / \mathrm{kWh}$ (DL 363/2007) and at present around to $0.09 € / \mathrm{kWh}$ while the electricity prices for the residential sector increases (the final consumer electricity price is $0.16 € / \mathrm{kWh}$ ) [8]. Taking into account this situation, generating electricity on-site on the household is more attractive than feeding into the grid. In order to increase the use of solar energy in selfconsumption and to reduce the risks on the electrical grid

\footnotetext{
* Corresponding author: fpfp@fe.up.pt
} 
due to the intermittency of the renewable energy sources $[9,10]$, the microgeneration with PVs associated with batteries energy storage systems (BESS) is arising. This new market opened the opportunity to solve other problems caused by the necessity of reusing the batteries retired from the electrical vehicles (EV) and to reduce the upfront costs of EVs [11]. The combined use of the PVs and BESS also opened new fields of research that focus on the optimisation and sizing of the two technologies. Studies show that optimised systems could reduce the energy sent to the electrical grid by $76 \%$ and increase PVs renewable energy consumption by $78 \%$, decreasing the electrical bill by $87 \%$ [12]. These batteries have to be retired when they reach between 70 to $80 \%$ of their original capacity [9]. However, some researchers have shown that some batteries which reach the ageing knee would not have a second life [11]. On the other hand, [11] found that there is a gap in the literature related to the study of the second life battery ageing performance

The actual implementation of PV+BESS in buildings poses additional challenges as their efficiency will depend on occupant behaviour. However, due to the real market electrical tariffs in Portugal, and the actual prices of new BESS, a PV demand response sizing should be preferable [13]. The same authors also defend that a decrease in the BESS will make this alternative interesting, especially in cases where demand consumption is not easy to predict or is not known in the design stage.

The authors Lund (2018) [14] have analysed the optimal ratio of energy storage to the share of selfconsumed PV electricity in eight locations with different demand profiles and solar radiation. Irrespective of climate the optimum rate vary between $0.5-2 \mathrm{Wh} . \mathrm{Wp}^{-1}$.

In the study of Korkas, Baldi, Michailidis and Kosmatopoulos (2016) [15], the authors found a gap in the literature related to the consideration of occupant behaviour in the optimisation of micro-grids with PV+BESS. The rationale of the work was the consideration of the demand in a dynamic way, based in the occupant behaviours related to their thermal comfort. The algorithm proposed improved the use of renewable energy between $12-22 \%$ without sacrificing the occupant requirements for thermal comfort.

In this paper, a modular nZEB with PV energy onsite generation and with second life EV Li-Ion batteries will be studied. The main focus of the paper is to analyse the impact of the energy-centric occupant behaviours into the state of charge (SOC) of the BESS.

\section{Methods}

\subsection{Case Study}

The case study under analysis is a prototype home that was built in an industrial environment and transported to the campus of the University of Porto by truck (Fig. 1). The prototype has a floor area of $27 \mathrm{~m}^{2}\left(11 \mathrm{~m}^{2} \times 3,2 \mathrm{~m}^{2}\right)$ and a height of $2.5 \mathrm{~m}^{2}$ (Fig. 2). It has one room, one bathroom and an open space with the kitchen and the living room. It was constructed with structural insulated panels (SIP) structurally reinforced with a light steel frame (LSF).

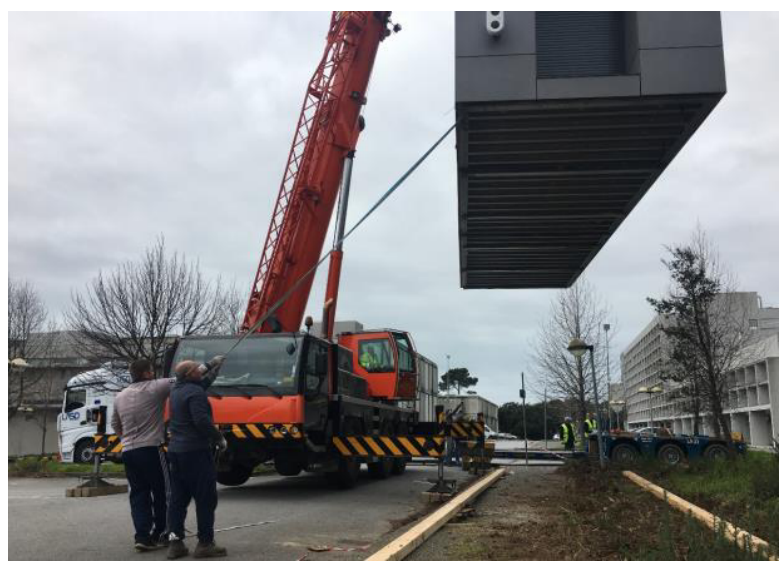

Fig. 1. Placing of the house in the University campus.

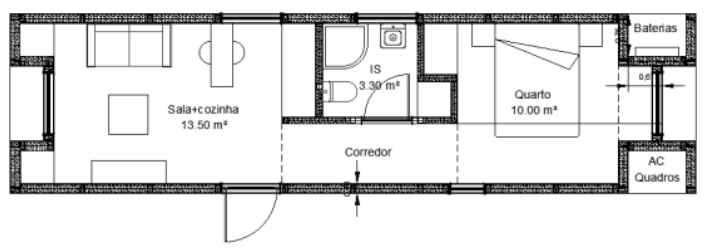

Fig. 2. Design of the prototype.

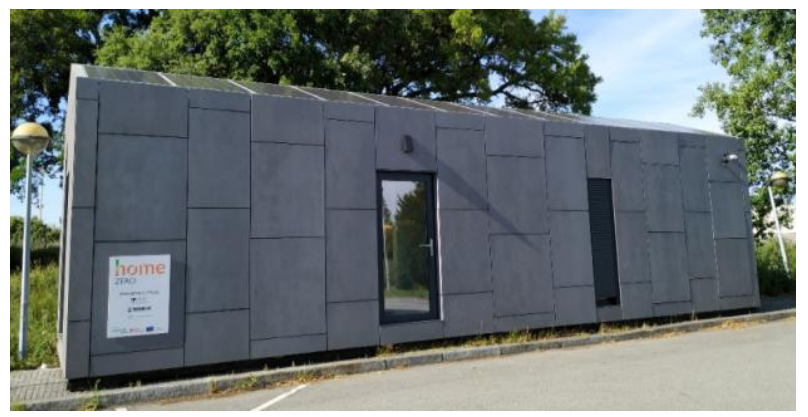

Fig. 3. Case study.

Table 1 resumes the thermal resistance of the construction elements of the exterior envelope. The prototype has an on-site renewable energy production with 12 PVs modules installed on the roof (Fig. 3). Each PV module has an efficiency of $17.52 \%$, use polycrystalline silicon solar cells $(156 \times 156 \mathrm{~mm})$ and have a nominal power (Pmax) of $270 \mathrm{~W}$. The prototype also has a BESS using second life Lithium-Ion (Li-Ion) batteries, reused from an EV. The original EV battery had an energy capacity of $24 \mathrm{kWh}$ with $400 \mathrm{VDC}$. In order to obtain a 45VDC (nominal) system, 12 battery modules were mounted together in a series/parallel set. The battery pack then has a capacity of $120 \mathrm{Ah} / 6 \mathrm{kWh}$ with a maximum voltage $50 \mathrm{~V}$ and a minimum voltage of $42 \mathrm{~V}$. It weighs approximately $48 \mathrm{~kg}$ and a nominal voltage of $45 \mathrm{~V}$ (Fig. 4). 
Table 1. Thermal properties of building components.

\begin{tabular}{|c|c|}
\hline Building component & Thermal resistance \\
\hline Exterior walls & $4.27 \mathrm{~m}^{2} .{ }^{\circ} \mathrm{C} / \mathrm{W}$ \\
\hline Roof & $6.43 \mathrm{~m}^{2} .{ }^{\circ} \mathrm{C} / \mathrm{W}$ \\
\hline Floor & $1.50 \mathrm{~m}^{2} .{ }^{\circ} \mathrm{C} / \mathrm{W}$ \\
\hline
\end{tabular}
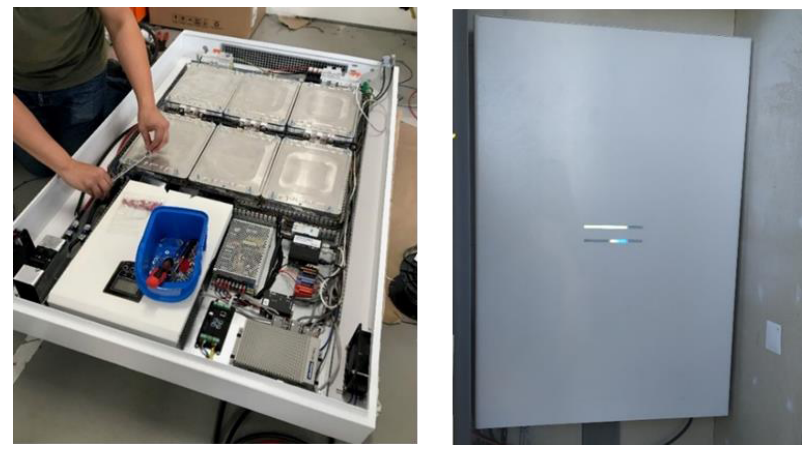

Fig. 4. BESS of the prototype.

\subsection{Energy management System}

The energy control, which will be done by the software included in the prototype on-board computer, first involves communicating with the various system components and taking readings of the available energy sources - solar and batteries (Fig. 5). The components from which this energy information is obtained are the inverter, the Battery Management System (BMS), a meter for reading household consumption and a wall-box for charging an EV. A responsive web application has also been developed to view the status of a device in real-time, the history of production and consumption over time, as well as to make certain operating configurations remotely (Fig. 6).

The prototype was equipped with an indoor environmental monitoring system composed by temperature, relative humidity and $\mathrm{CO}_{2}$ sensors and energy meters. In the outdoor was placed a weather station with temperature, relative humidity, solar radiation and precipitation.

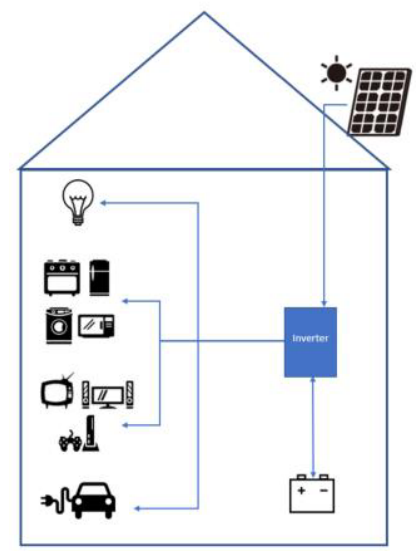

Fig. 5. Scheme of a house controlled by an EMS.

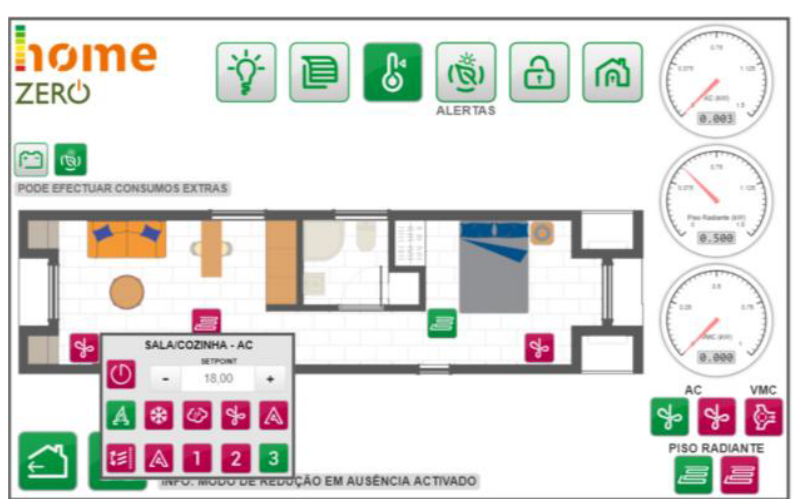

Fig. 6. Web application dashboard.

\subsection{Occupancy profiles}

For a detailed analysis of the occupants' impact on the state of charge of the prototype, four occupancy profiles of the same occupants were proposed. Each profile was monitored for five days each from a cooling period of the year:

- Occupation type 1 - Free running Profile;

- Occupation type 2 - No Occupation;

- Occupation type 3 - Only HVAC were activated to improve the indoor conditions (no setpoints);

- Occupation type 4 - Only windows and door were used to improve the indoor environment.

In the three occupancy types with occupancy, the number of occupant were equal and composed by three adults with a total methabolist around 2.85 met.

The occupants could turn on the lights whenever they wanted, and constant consumption of an appliance of approximately $250 \mathrm{~W}$ of power was present in all the profiles.

Since the monitoring periods were different, the solar radiation monitored in that period was compared, and no substantial differences were found (Fig. 7). The exterior temperature has not the same daily pattern during the monitoring period, but it has not the most preponderant factor influencing the indoor temperature.

The case study was occupied by three adults during the day. The adults used the prototype as an office to study. PIR and $\mathrm{CO}_{2}$ sensors were used to detect the occupants' presence. The operation of appliances was monitored through the energy meters, and the windows and doors operation was detected with reed switch sensors. 


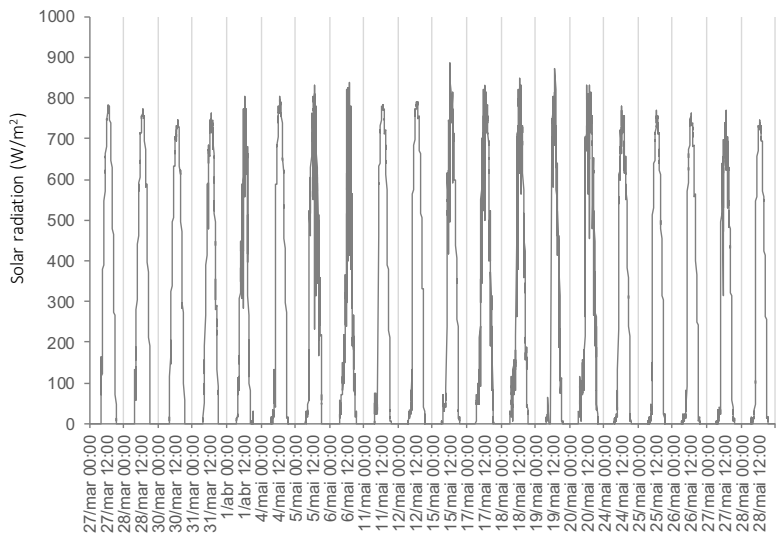

Fig. 7. Solar radiation registered during the 20 days.

\section{Results and Discussion}

\subsection{Monitored indoor temperature}

The mean indoor temperature recorded during the five days of occupancy of each type is represented in Fig. 8. Occupancy type 2 (which represents the period without occupancy) is the most different from the four. Without occupancy, the prototype has indoor mean temperatures very similar during the day, around $20^{\circ} \mathrm{C}$. However, it can also be seen that Occupancy type 4, that only allows using doors and windows operation to improve indoor temperature lead to always higher temperatures. The Occupancy Type 3, which only used the HVAC systems to condition indoor temperature, presented a variation within $25^{\circ} \mathrm{C}$ and $20^{\circ} \mathrm{C}$.

During the frequent occupancy period, from 9 am to $6 \mathrm{pm}$, the temperature data shows similar behaviour. The main significant difference can be seen after 3 pm when Occ. Type 3 temperature does not go above near $25^{\circ} \mathrm{C}$.

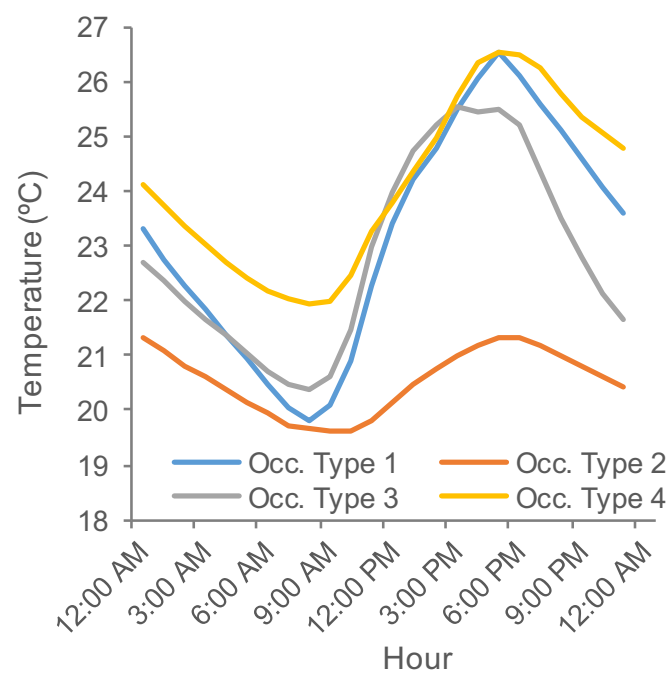

Fig. 8. Mean indoor temperature by type of occupancy (24h).

Considering all the collected data (Fig. 9), occupancy type 2 is detached, having the lowest temperature values.
The two occupancy types with the use of mechanical equipment (Occ. Type 1 and Occ. Type 3) presented very similar values between quartile 1 (Q1) and quartile 3 (Q3). The occupancy type that relied only on passive means to condition the indoor environment conditions (Occ. Type 4) presented higher temperatures.

The temperature registered in the unoccupied profile shows that the occupancy is responsible for the major internal loads. In the period of unoccupancy, the exterior temperature have not presented the lower values.

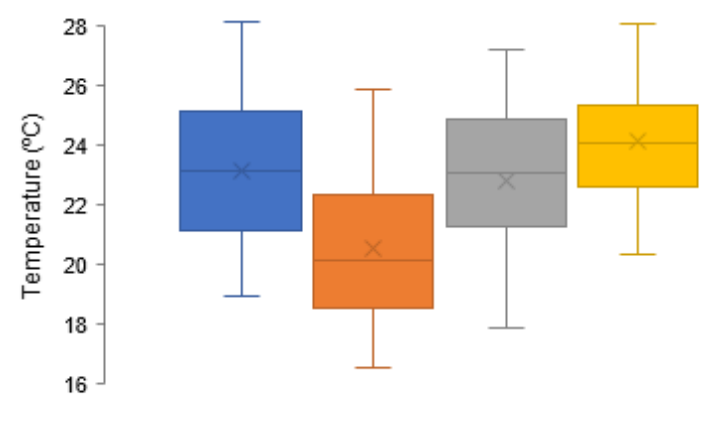

Fig. 9. Registered indoor temperature by type of occupancy.

\subsection{Battery state of charge}

\subsubsection{Occupant profiles}

The distribution of the state of charge (SoC) of the battery during the monitored periods, corresponding to the different occupancy profiles, can be seen in Fig. 10. As can be seen, the occupancy profile that only used mechanical systems (Occ. Type 3) leads to a larger variation of the battery SoC. This profile has a mean value bellow the Q1 of the other profiles. It can also be seen that the battery is only fully charged around the Q3. The occupancy types 2 and 4, unoccupied and only using passive systems, lead to identical SoC distributions. Profile type 3 (free use of mechanical and passive systems) lead to a wider distribution of the SoC.

The results in Fig. 10 clearly show the impact on the battery SoC promoted by the occupant actions to achieve thermal comfort. Even so, the possibility to reach comfort conditions using only renewable energy during the cooling season was possible in this case. 


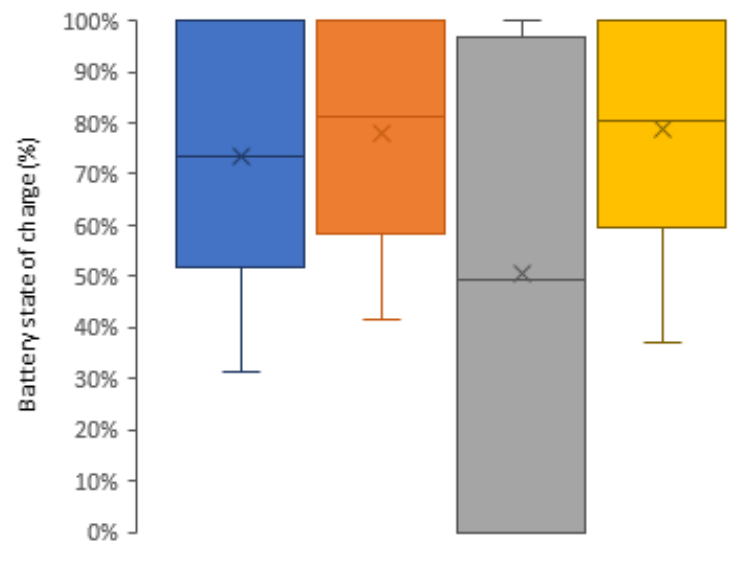

Occ. Type $1 \square$ Occ. Type $2 \square$ Occ. Type $3 \square$ Occ. Type 4

Fig. 10. Battery SOC by type of occupancy.

The $24 \mathrm{~h}$ mean SoC analysis for each profile (Fig. 11 ), helped to see that the occupancy type 3 has a mean value consistently lower than the other SoC profiles in the 24 hours having a mean value $30 \%$ below. Occupancy types 2 and 4 have a $24 \mathrm{~h}$ similar behaviour varying only from $3 \mathrm{am}$ to $9 \mathrm{am}$, and between $6 \mathrm{pm}$ to 12 am, no more than $5 \%$. These low differences can be explained by the different consumptions in the appliance present in all the profiles since the SoC profile in the daylight is the same for occupancy type 2 and 4 . The profile of occupancy type 1 started to decrease the value of SoC from $100 \%$ when the solar energy could not, at least, equal the electrical consumption of the occupants (3 pm).

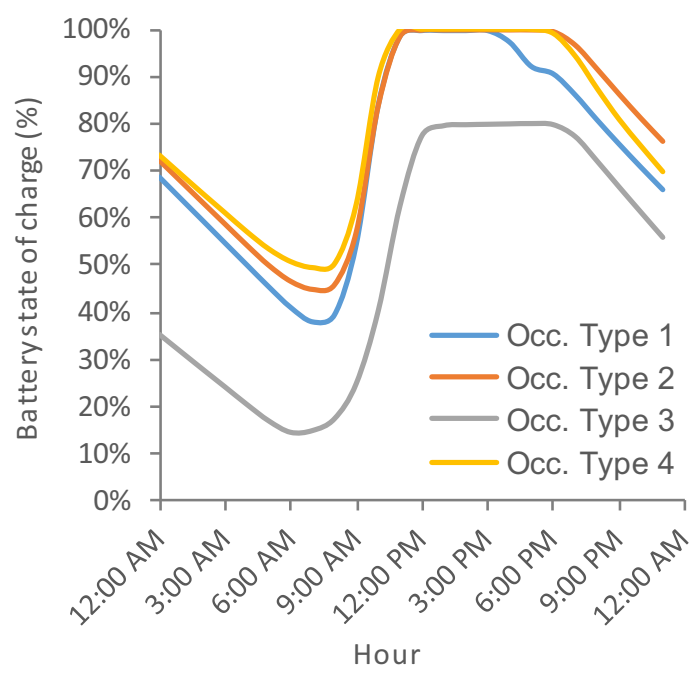

Fig. 11. 24h SoC mean value per occupancy profile.

The instant of the start of charging of the BESS varies over the monitored months, starting earlier in the summer months and later in the spring/fall months. On average, the latest loading occurs in September at around 9 am, and early loading starts in June at 8 am (Table 2). Considering the instant in which the batteries begin to discharge, it begins earlier in the spring/fall and later in the summer. On average, the earliest discharge beginning occurs in October, around 4:30 pm and the later in June after 6:30 pm (Table 2).

In average, the upper and lower changing beginnings had a displacement of over 1 hour and the discharging a displacement above 2 hours.

Table 2. Mean hour for charging and discharging and standard deviation.

\begin{tabular}{|c|c|c|}
\hline Month & Start charging & Start discharging \\
\hline March & $8.6 \pm 0.6$ & $17.7 \pm 0.8$ \\
\hline April & $8.3 \pm 0.6$ & $18 \pm 0.7$ \\
\hline May & $8.3 \pm 0.7$ & $18.1 \pm 0.7$ \\
\hline June & $7.9 \pm 0.7$ & $18.7 \pm 0.3$ \\
\hline July & $8.3 \pm 0.8$ & $18.4 \pm 0.4$ \\
\hline August & $8.8 \pm 0.7$ & $18.1 \pm 0.3$ \\
\hline September & $9.1 \pm 0.4$ & $17.5 \pm 0.4$ \\
\hline October & $8.8 \pm 0.4$ & $16.5 \pm 0.9$ \\
\hline
\end{tabular}

\subsubsection{Meteorological impacts}

Independently to the occupant profile considered, it is possible to highlight the differences in SoC of the batteries comparing the mean value of the state of charge of the batteries in days without rain and days with rain (Fig. 12). The difference registered between days with rain and without rain in the batteries SoC varies between 10 and $30 \%$. The days without rain reaches in mean the state of fully charged at noon and only starts its discharge after $6 \mathrm{pm}$. The days with rain has in mean an upper value of the state of charge of $70 \%$.

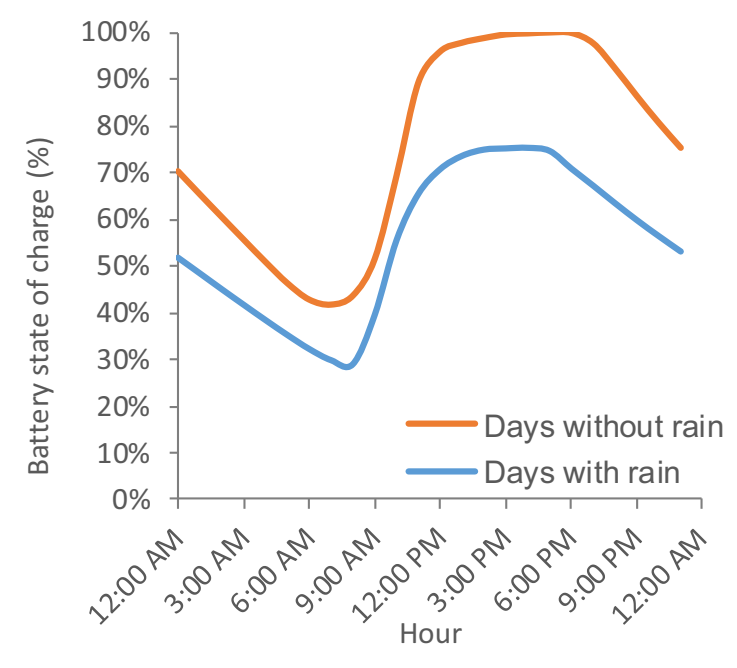

Fig. 12. Battery state of charge considering one rainy month and one month without rain. 


\section{Conclusions}

This study analysed the impact of the energy-centric occupant behaviours into the state of charge (SoC) of the BESS. A modular nZEB with PV energy on-site generation and with second life EV Li-Ion batteries was used as case study. It was possible to detect and quantify the impacts of a set of four occupancy types: passive and active occupant behaviour; unoccupied building; exclusive activation of HVAC systems; exclusive use of windows and door. From the results obtained, it was possible to conclude the following:

- Indoor temperature was influenced by occupancy type. Only values from Q1 to Q3 were found in the range of $20^{\circ} \mathrm{C}$ to $25^{\circ} \mathrm{C}$ in the occupancy profile 1,3 and 4 , corresponding to the periods where there was occupancy. Profile 3, which used air conditioning and centralised mechanical ventilation (VMC) equipment, was the one that led to a shorter range of the indoor temperature. The highest values of average temperature were reached in the type profile that only used passive systems.

- The SoC varies considerably depending on the type of occupancy and the associated power consumption. The profile that allowed used climate control systems led to much lower battery states than the other profiles. Passive, mixed and unoccupied profile led to similar SoC profiles.

- Occupant behaviour was revealed as a determinant factor on the SoC of the batteries. The occupancy type that uses more energy lead to a SoC consistently below (over 30\%) considering the 24 hours analysis.

- Higher consumptions of energy in HVAC did not improved considerably the thermal comfort.

- The state of charge of batteries varies considerably depending on the day solar radiation. The batteries SoC in rainless days were compared with the rainy days and $\mathrm{SoC}$ in the rainy days were, in averages, from $10 \%$ to $30 \%$ below.

In future, we are trying to create occupant profiles with more time span and covering all the seasons, studying its impact on the SoC. Another opportunity that we are exploiting is the long time performance of the second life batteries in order to contribute to this gap found in literature.

This work was financially supported by CONSTRUCT Instituto de I\&D em Estruturas e Construções funded by national funds through the FCT/MCTES (PIDDAC) [grant number UID/ECI/04708/2019] and European Regional Development Fund (ERDF) [grant number POCI-01-0247FEDER- 017840], through the Operational Programme for Competitiveness and Internationalization (COMPETE 2020), under the PORTUGAL 2020 Partnership Agreement HOME.

\section{References}

1. Republic, C.o.t.P., National Renewable Energy Policy. 2009.

2. 2010/31/EU, D.,

3. K. Bot, N.M.M. Ramos, R.M.S.F. Almeida, P.F. Pereira, C. Monteiro, J. Build. Eng., 24, p. 100769 (2019)
4. 2018/844/EU, D.,

5. 2002/91/CE, D.,

6. J. Kanters, M. Wall, Renew. Sustain. Energy Rev., 57, p. 173-185 (2016)

7. A. Sani Hassan, L. Cipcigan, N. Jenkins, Appl. Energy, 203, p. $422-441$ (2017)

8. S. Rodrigues, F. Faria, N. Cafôfo, X. Chen, H. Mata-Lima, F. Morgado-Dias, J. of Clean Energy Technol., 5(1), p. 52-59 (2017)

9. M.A. Cusenza, F. Guarino, S. Longo, M. Mistretta, M. Cellura, Energy Build., 186, p. 339-354 (2019)

10. Y. Yang, S. Bremner, C. Menictas, M. Kay, Renew. Sustain. Energy Rev., 91, p. 109-125 (2018)

11. E. Martinez-Laserna, I. Gandiaga, E. SarasketaZabala, J. Badeda, D.I. Stroe, M. Swierczynski, A. Goikoetxea, Renew. Sustain. Energy Rev., 93, p. 701-718 (2018)

12. F.M. Vieira, P.S. Moura, A.T. de Almeida, Renew. Energy, 103, p. 308-320 (2017)

13. G. Lorenzi C.A.S. Silva, Appl Energy, 180, p. 524535 (2016)

14. P.D. Lund, J. Energy Stor., 18, p. 218-228 (2018)

15. C.D. Korkas, S. Baldi, I. Michailidis, E.B. Kosmatopoulos, Appl Energy, 163,p. 93-104 (2016) 